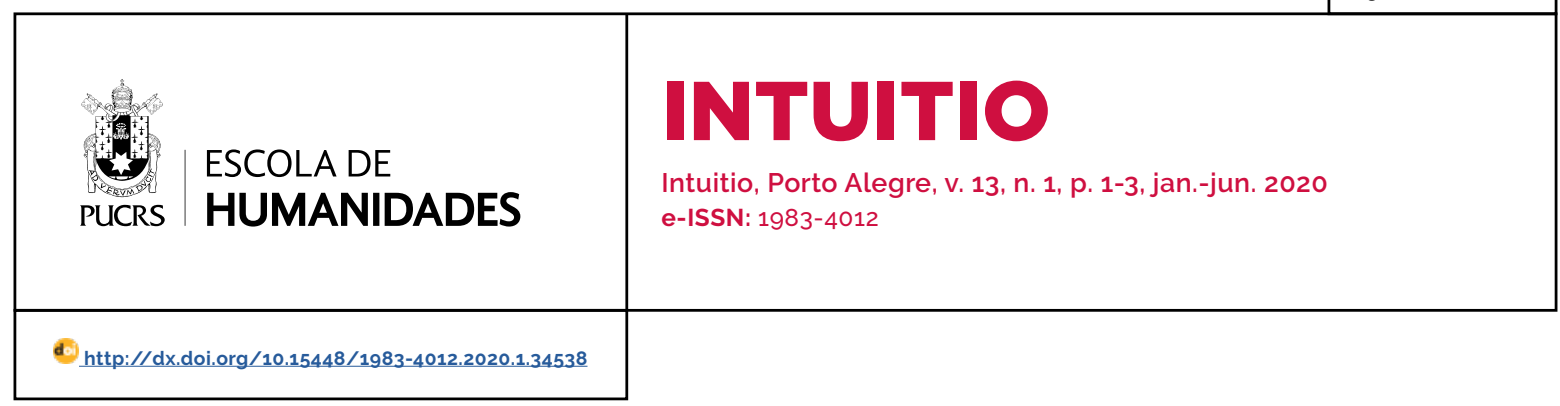

RESENHA

\title{
MICHAELIAN, Kourken. Mental Time Travel: Episodic Memory and Our Knowledge of the Personal Past. Cambridge, MA: The MIT Press, 2016
}

\section{Bruna Natália Richter ${ }^{1}$ \\ orcid.org/0000-0002-7946-7249 \\ brunataliarichter@gmail.com}

Recebido em: 16 jul. 2019. Aprovado em: 20 nov. 2019 Publicado em: 27 jul. 2020.

\section{(c) (1)}

Artigo está licenciado sob forma de uma licença Creative Commons Atribuição 4.0 Internacional.
O livro Mental Time Travel: Episodic Memory and Our Knowledge of the Personal Past, de Kourken Michaelian, é dividido em quatro partes. Cada uma tem como objetivo tratar das principais teorias que discutem sobre a memória episódica.

A primeira parte, chamada de Epistemology and Human Memory, pretende discutir o processo de rememoração como um modo de simulação da viagem no tempo mental, assim como na confiabilidade desse sistema. A segunda parte, Episodic Memory as Mental Time Travel, aponta que a teoria do senso comum e a teoria causal da memória devem ser abandonadas dadas as suas inadequações em relação aos recentes estudos, que apontam como a memória episódica é uma instância de um sistema cognitivo mais amplo de construção de cenários mentais. A terceira parte, Mental Time Travel as a Source of Knowledge, discute sobre a confiabilidade da memória episódica. E a quarta parte, chamada The Evolution of Mental Time Travel, aborda as recentes pesquisas sobre a viagem no tempo mental como uma capacidade evolutiva que pode ou não estar presente nos animais não humanos.

Na primeira parte de seu livro, Michaelian analisa algumas das taxonomias de memória para situar e explicar a memória episódica em contraste aos demais tipos de memória. Essa discussão visa compreender o motivo da lembrança compreendida como um todo não poder ser vista como um tipo natural.

Para ser considerada como um tipo natural tanto a memória declarativa quanto a não-declarativa, por exemplo, memória motora, priming, memória semântica e a memória episódica deveriam compartilhar de um mesmo padrão ou sistema cognitivo, o que não é o caso. Desse modo, uma abordagem unificada sobre o conhecimento memorial não é possivel.

Assim sendo, Michaelian passa a tratar sobre a importância da confiabilidade para o processo de rememoração. A confiabilidade, pretendida por ele, é embasada nas descobertas psicológicas sobre como ocorre o processo de rememoração e de imaginação de episódios. Portanto, 
a epistemologia será aplicada e naturalizada por meio dos processos de rememoração.

Em um segundo momento, Michaelian apresenta as principais teorias sobre a memória episódica, a teoria do senso comum e a teoria causal da memória. A teoria do senso comum afirma que a representação endossada pela memória deve ter um conteúdo semelhante à experiência do evento que a gerou. Sendo assim, não é capaz de diferenciar entre alguns casos de rememoração e de imaginação que podem ser apresentados como contra-exemplo.

Já a teoria causal pressupõe uma conexão entre a representação anterior do sujeito e a sua imagem presente como sendo uma condição necessária para a rememoração. Essa conexão causal é realizada por um traço de memória. Algumas versões dessa teoria conseguem abordar melhor as críticas que são baseadas nas recentes descobertas sobre os processos de rememoração e imaginação, assim, permitindo modificações e novas informações que não estavam contidas na representação anterior.

Não obstante, a teoria pretendida por Michaelian, a simulacionista, afirma que a memória episódica é uma instância de uma capacidade mais geral de viagem no tempo mental que nos permite re-experienciar eventos que já ocorreram e pré-experienciar aqueles que podem vir a ocorrer. As informações são as mesmas para ambos os processos: tais informações são flexiveis e permitem a recombinação dos seus elementos e experiências anteriores. A viagem no tempo mental enfatiza as caracteristicas fenomenológicas como a consciência autonoética, que é a consciência do si mesmo em relação aos processos de viagem no tempo mental, e a cronestesia, que é a consciência do tempo subjetivo em que o sujeito está viajando.

O processo construtivo de rememoração é confiável mesmo que apresentando diferenças entre às informações da experiência originária do evento com a rememoração desse mesmo episódio, pois estas diferenças são compativeis com a confiabilidade. Esse processo de rememoração incorpora informações provindas de outras fontes, como no caso do testemunho.

Segundo Michaelian, essas incorporações aumentam a confiabilidade do processo de memória, dado que a incorporação é quase sempre algo que pode ser controlado pelo sujeito que deve ser sensivel à honestidade, à competência e à acurácia dos testemunhos. Para desenvolver uma melhor explicação e avaliação dessas novas informações, ele apela para a estrutura de monitoramento de fonte. Esse modo pretende diferenciar os processos de rememoração de episódios já experienciados e rememoração de episódios imaginados. Isso se dá a partir de um sistema metacognitivo em que é possivel diferenciar entre o nível do objeto e o meta-nivel envolvidos no monitoramento.

A abordagem do monitoramento do método pretende analisar o tipo de informação armazenada durante os processos de memória, pois a fonte em que ela foi gerada não é salva com o conteúdo, mas pode ser lida durante a rememoração. Esse monitoramento de processo visa analisar diferentes tipos de critérios envolvidos na viagem no tempo mental, como crenças, emoções, intenção, espontaneidade, entre outros.

Na quarta parte do livro, Michaelian aborda as formas de consciência relacionadas aos diferentes tipos de memória. O autor trata da relação do sentimento de passadidade no processo de rememoração, assim como a origem desse sentimento na cronestesia ou tempo subjetivo.

Neste caso estão envolvidos na memória duas formas de consciência, a autonoética, que é responsável pela consciência de si mesmo, e a cronestesia que é a consciência dos episódios experienciados no tempo subjetivo. A validade desses sentimentos é limitada, pois a cronestesia, como uma habilidade de localizar os episódios no tempo subjetivo, não é um critério que nos permite diferenciar a memória da imaginação; ela, apenas, nos informa se o cenário construido é atual ou contrafactual ou se a experiência pertence a nossa experiência ou a de outro sujeito.

Essas duas formas de consciência podem ser encontradas na memória dos seres humanos como elementos que a diferencia da que os 
demais animais possuem. Processos cognitivos como a viagem no tempo mental não podem ser realizados pelos animais não humanos, pois esses não possuem uma consciência do tempo subjetivo sofisticada o suficiente para tal processo.

Michaelian também apresenta os recentes estudos que afirmam que a viagem no tempo mental como um sistema cognitivo de construção de cenários mentais não apresenta uma diferenciação entre seus processos de rememoração e de imaginação. A diferenciação só é realizada através dos processos de monitoramento de fonte e dos processos mentais.

O livro tem como virtude ser uma ótima introdução às principais teorias e problemas que envolvem a memória episódica e a viagem no tempo mental. A teoria simulacionista pretendida por Michaelian é umas das teorias mais embasadas em descobertas provindas das neurociências, sem deixar de lado a busca pela confiabilidade dos conhecimentos de memória. A viagem mental no tempo faz parte de um sistema cognitivo mais amplo de construções de cenários mentais, em que suas capacidades mais discutidas são a memória episódica e a imaginação episódica.

Cada uma das partes do livro cumpre o que propõe, apresentando os principais problemas e explanações de forma concisa; além de agregar elementos e apontar os melhores caminhos para serem seguidos para quem pretende estudar os processos de rememoração e imaginação. No que concerne à consciência do tempo subjetivo, a discussão não é satisfatória como apontada pelo próprio autor, pois não há uma clara definição e nem mesmo uso especifico sobre a noção de sentimento de passadidade.

A discussão sobre o tempo subjetivo é muito ampla e frutifera na metafísica e trata sobre vários dados e experimentos provindos das neurociências. Entretanto, não há nenhum relato da existência desse sentimento de passadidade. ${ }^{2}$ O aspecto temporal da memória episódica é visto como fazendo parte da fenomenologia da recordação e não do seu conteúdo.

\section{REFERÊNCIAS}

MICHAELIAN, Kourken. Mental Time Travel: Episodic Memory and Our Knowledge of the Personal Past. Cambridge, MA: The MIT Press, 2016. https://doi.org/10.7551/ mitpress/105.01.001.0001.

WITTMANN, Marc. Felt time: the psychology of how we perceive time. Tradução Erik Butler. Cambridge, MA: MIT Press, 2015

\section{Bruna Natália Richter}

Doutoranda no Programa de Pós-Graduação em Filosofia da Universidade Federal de Santa Maria.

\section{Endereço para correspondência:}

Bruna Natália Richter

Universidade Federal de Santa Maria

Av. Roraima n 1000, CCSH II, PRÉDIO 74

Cidade Universitária - Camobi

Santa Maria - RS

CEP: $97105-900$ 